\title{
Oxidation Resistant Cast Iron for High Temperature Application Nico Scheidhauer ${ }^{1, a^{*}}$, Claudia Dommaschk ${ }^{1, b}$ and Gotthard Wolf ${ }^{1, c}$ \\ ${ }^{1}$ Bernhard-von-Cotta-Str. 4, 09599 Freiberg, Germany \\ aNico.Scheidhauer@gi.tu-freiberg.de, 'blaudia.Dommaschk@ifg.tu-freiberg.de, 'Gotthard.Wolf@gi.tu-freiberg.de
}

Keywords: Aluminum alloyed ferritic SiMo cast iron, oxidation resistance, oxide layer thickness, austenitic D5S

\begin{abstract}
This paper focusses on the development of materials for exhaust gas components. The present work will focus on a ferritic SiMo-cast iron to create an economic alternative to the austenitic D5S. Aluminum and silicon are essential for this material development because they increase the transformation temperature. They also improve the durability of the protective oxide layer. Additionally, aluminum improves the high temperature mechanical properties by precipitation of a kappa-phase. The ferritic SiMoAl cast iron shows very good oxidation resistance and also mechanical properties.
\end{abstract}

\section{Introduction}

Based on the material costs connected to the mechanical, physical and chemical properties, the development of materials for exhaust gas components in combustion engines is promoted.

SiMo cast iron is one of the most economic iron-based materials for high temperature applications, characterized by a good castability and cheap alloying elements. This is the reason why SiMo-4.1 was chosen for this reported material development. The aim was to develop a new ferritic material with a wide range of use, comparable to the most used cast iron for high temperatures, the austenitic D5S. The new alloy has to resist temperatures up to $950^{\circ} \mathrm{C}$ without any transformation from ferrite to austenite and it has to fulfill some needs based on the mechanical, chemical and physical properties. The most important of these properties are tensile strength, creep resistance at elevated temperatures and thermal expansion coefficient. Due to the large number of properties that have to be analyzed for material development the present work will mainly focus on the oxidation resistance.

Aluminum and silicon are known as elements which increase the transformation temperature. They also improve the durability of the protective oxide layer of cast iron and steel alloys but they also increase the embrittlement of the material. Furthermore, aluminum is considered as detrimental element in ductile iron, as it disrupts the spherical graphite formation.

\section{Basic Principles}

Oxidation resistance has three basic advantages. At first, it is essential for the lifetime of the casting because it avoids the reduction of the bearing cross section below a critical level. Another point is that damage at the casting and moving parts can be prevented because less or no oxide particles are spalled of from the casting surface and accelerated by the gas flow. Last but not least advantage is the preservation of the air flow and heat transfer conditions in exhaust gas manifolds and turbochargers. They are created with optimized design and if oxide skin formation is suppressed the air flow and heat transfer are not modified to worse values. In this case, the efficiency and the maximum loading pressure will stay at a high level.

In the literature two mechanisms of scale growth are reported, see Fig. 1(a). The first one is promoted by diffusion of metal ions to the interface between oxide scale and the surrounding atmosphere (steps 1. to 5.). The second one instead is characterized by the diffusion of oxygen through the oxide layer to the metal (steps 8. to 10.). Generally, oxidation processes are mixed forms of both mechanisms. The growth mechanisms always depend on the alloying elements, oxide 
film density, brittleness, adherence, temperature and if there is a static temperature field or cyclic temperature treatment.

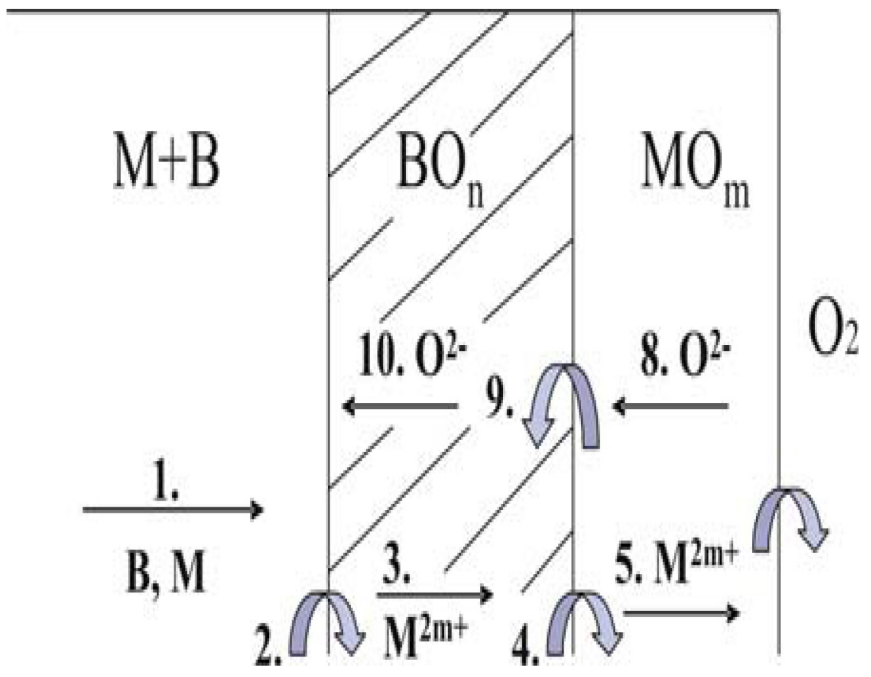

(a) Oxide growth behavior of alloys [1]

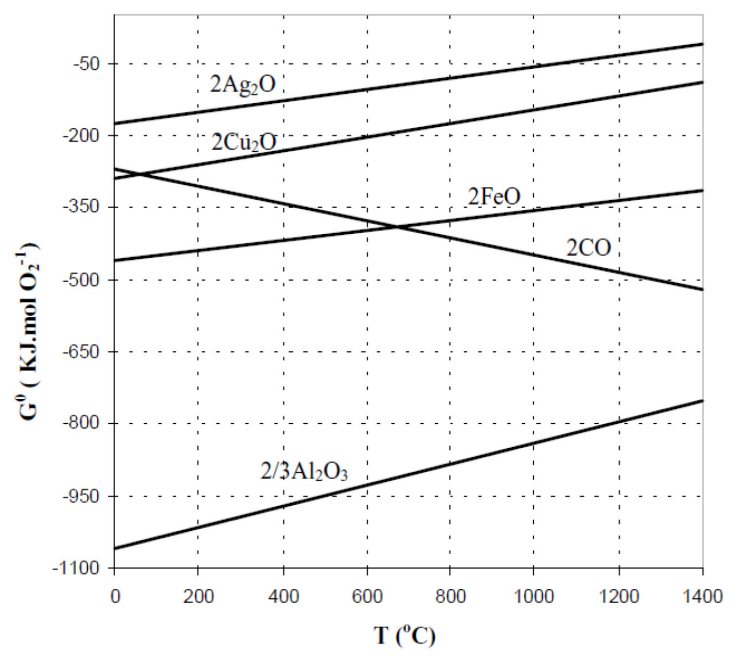

(b) Ellingham-Richardson diagram [2]

Figure 1: Oxide growth behavior of alloys and Gibbs free energies of oxide formation

The driving force for oxidation is the Gibbs free energy. If it is below a level of 0 a metal is oxidized. This relation is graphically illustrated in the Ellingham-Richardson-Diagram (Fig. 1(b)). In this diagram it is shown, that aluminum, is oxidized faster than iron due to the lower free energy. Silicon and also chromium have values of Gibbs free energy lower then $\mathrm{FeO}$ but higher than $\mathrm{Al}_{2} \mathrm{O}_{3}$. These three elements form continuous oxide layers which prevent the metal or alloy from further oxidation [3]. If an alloy is oxidized the scale composition is dependent on the single Gibbs free energies of the referring elements but also on their content. The element with the lowest Gibbs energy has the biggest affinity to oxygen. But aluminum and silicon content in alloyed cast iron is low compared to the iron content. So at first a $\mathrm{FeO}-\mathrm{Fe}_{2} \mathrm{O}_{3}$ layer with low density is formed and ruptured by vaporizing $\mathrm{CO}$ gas. Further oxidation leads to the formation of aluminum and silicon oxide that makes the oxide layer more and more dense by the formation of $\mathrm{AlFeO}_{3}$ and $/$ or $\mathrm{FeSiO}_{4}$. Growth and sintering of smaller $\mathrm{Fe}, \mathrm{Al}$ and $\mathrm{Si}$ rich oxide particles produce a continuous oxide layer which acts as a diffusion barrier to further oxidation [4]. Oxidation can continue at areas where micro cracks or gaps appear. Because of that mechanical damage, differences in temperature and a wide range of the chemical composition of the oxide layer should be avoided. $[1,5]$

\section{Experimental Procedure}

The material development was supported by phase simulation with JMatPro, which is using the CALPHAD-method to calculate phase diagrams and precipitated phases. Based on these first results the best composition of cast iron alloyed with aluminum was tested in detail. Concurrently to this, a basic but essential research was done to determine the influence of the most important alloying elements on the new high temperature resistant cast iron, which are silicon and aluminum. The structure of the whole research is shown in Tab. 1. 
Table 1: Experimental research

\begin{tabular}{|l|}
\hline \multicolumn{1}{|c|}{ Basic research } \\
\hline - Lamellar graphite \\
- Without magnesium treatment \\
- C: $3,1 \%$; Si: $0-4,5 \% ; \mathrm{Al}: 0-9 \%$ \\
- Analysis of oxide layers, Ac1 temperture \\
and hardness \\
\hline
\end{tabular}

\section{Material development}

- Vermicular to globular graphite

- With magnesium treatment

- $\mathrm{C}: 2,5-3,5 \%$; Si: $>2,5 \%$; Al: $>4 \%$; Mo, $\mathrm{V}$, $\mathrm{Nb}, \ldots$

- Analysis of mechanical, chemical and physical properties

For the oxidation tests with weight gain measurement, specimens of $20 \mathrm{~mm}$ diameter and $5 \mathrm{~mm}$ length were used. Weight measurement accuracy was $\pm 0,1 \mathrm{mg}$. For the layer thickness measurement they were cut into half and ground to $1200 \mathrm{P}$. The specimens were oxidized in a resistance heated furnace in static air atmosphere for $96 \mathrm{~h}$ at $820^{\circ} \mathrm{C}$. This sample was embedded in gap-free hardening resin with the machined surface pependicular to the microscope analysis surface. Due to this handling, a crosscut of the oxide layer was the result which could be measured.

\section{Results}

Silicon and aluminum are direct neighbors in the PTE but their influence on cast iron differs a lot. It was confirmed, what A. R. K. Rashid and D. V. Edmonds [6] already described, that aluminum has a similar graphitizing influence on cast iron like silicon. But the influence of aluminum and silicon have different impacts on transformation temperature, hardness evolution and oxidation resistance of the cast iron. By increasing the silicon content over 1wt.- $\%$ the hardness is more uniform in contrast to the influence of aluminum. The hardness is increasing with rising aluminum content when it exceeds a level of $3 \mathrm{wt} .-\%$. This is because of the precipitated Fe-Al-C-X-kappa-phase, see dark grey particles in Fig. 2.

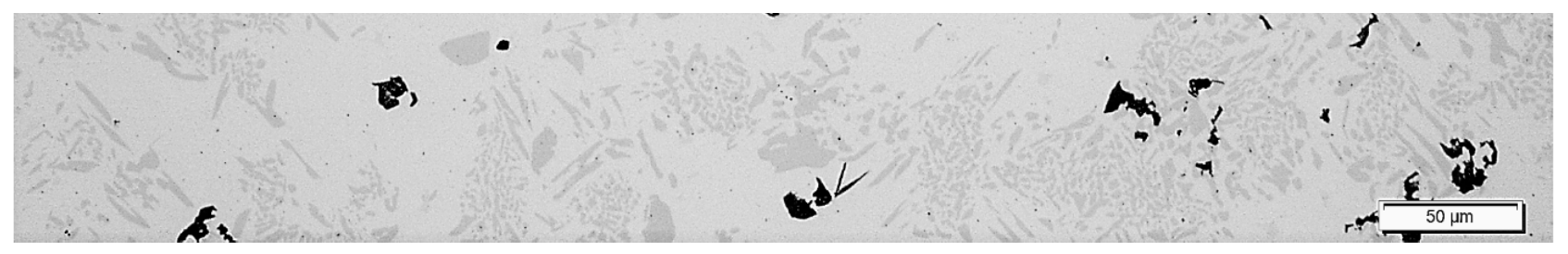

Figure 2: Microstructure of aluminum alloyed cast iron

In this case, the kappa-phase is distributed over the whole microstructure in two different shapes. A finely distributed and a compacted, brittle one which occurs at high aluminum contents above 5 wt.$\%$. The main components of this perlite like phase are $\mathrm{Fe}, \mathrm{Al}$ and $\mathrm{C}$. This phase is essential for the high temperature properties of the material, but it also influences the brittleness as well as the machining properties. Therefore, a compromise has to be found, that results in a limitation in maximum Al content.

Another effect occurred during the analyzation of the oxidation rate of the materials. In the first step, it was tried to be rated by weight gain measurements. But because of two crucial factors, it was impossible to rate the oxidation of the cast iron. At first, the oxide layer thickness is very low and there is not much weight gain due to it. The second large influence occurs because of the graphite morphology. Depending on the graphite structure (lamellar or vermicular), a random amount of carbon is oxidized to carbon monoxide and dioxide during the treatment. If those graphite structures are present, the oxidation process of the graphite and the alloy is easily led to the inside of the material. Because of that, it is almost impossible to rate the oxidation behavior by weight measurement and to compare results to other specimens. The results in Fig. 3 show that it is 
possible to get a weight loss while the oxide layer is growing, as it was already reported by M. J. Kadhim [3].

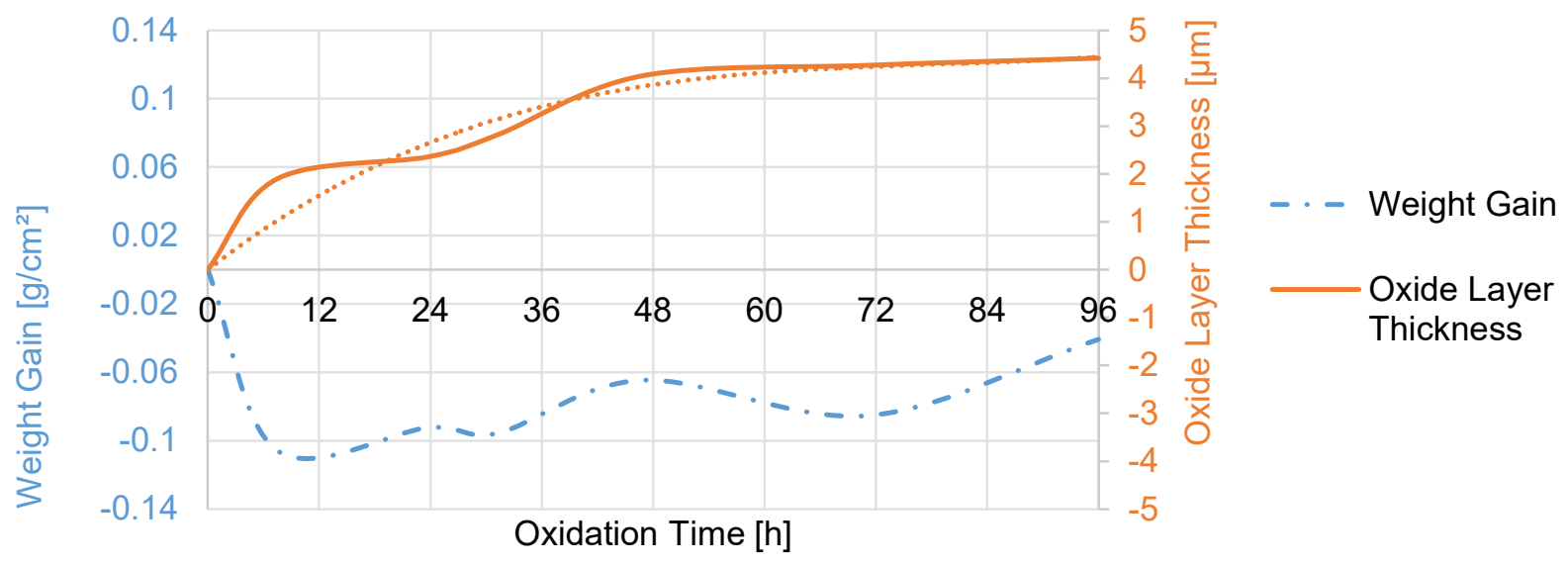

Figure 3: Al alloyed SiMo cast iron: weight gain measurement compared to oxide layer thickness

In the second step which was inevitable in this special case of very thin oxide layers and disrupted graphite morphology the layer thickness measurement was used. The comparison between the two measurement methods is shown in Fig. 3. It is obvious that for oxide layers with a thickness of only a few micrometers it is much more exact to measure the thickness of the oxide layer.

The REM analysis was made for the analysis of general oxide skin growth and their composition. Oxide skins for single aluminum and silicon alloyed cast iron that were analyzed for the basic research showed that scales are built up in at least two or more layers, as it is shown in Fig. 4.

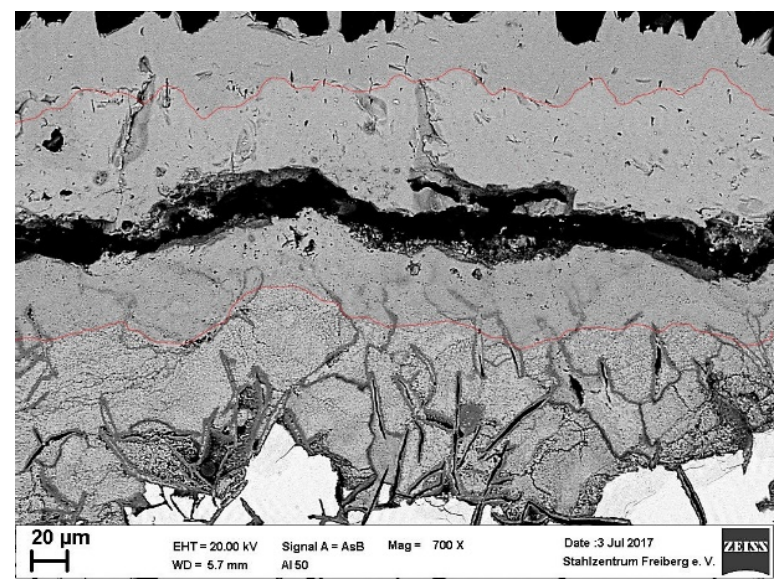

Figure 4: REM analyzation of the oxide layer of a 5wt.- $\% \mathrm{Al}$ alloyed cast iron, magnification: 700x

Close to the metal matrix the layer has a much higher aluminum and/or silicon content. Connected to the fact that oxide layers become less thick it could have been shown that both elements form more dense oxide layers that reduce the oxide layer growth. Cracks appear between the layers with biggest composition difference in aluminum or silicon content because of their different thermal expansion coefficients, as it can be seen in Fig. 4. The upper layer has an Al content of $1.3 \mathrm{wt} . \mathrm{\%}$ the lower includes $8.07 \mathrm{wt} .-\%$ Al. A further result was that depending on the graphite morphology a different amount of oxygen reached the inner metal matrix. A. R. K. Rashid and D. V. Edmonds [6] suggest that also the diffusion of oxygen is reduced. Due to that they found out that by addition of aluminum, the metal and carbon oxidation is reduced. It was shown at the basic research that silicon has the same effect because it reduces the oxygen content in the center of the cast iron specimens itself. 


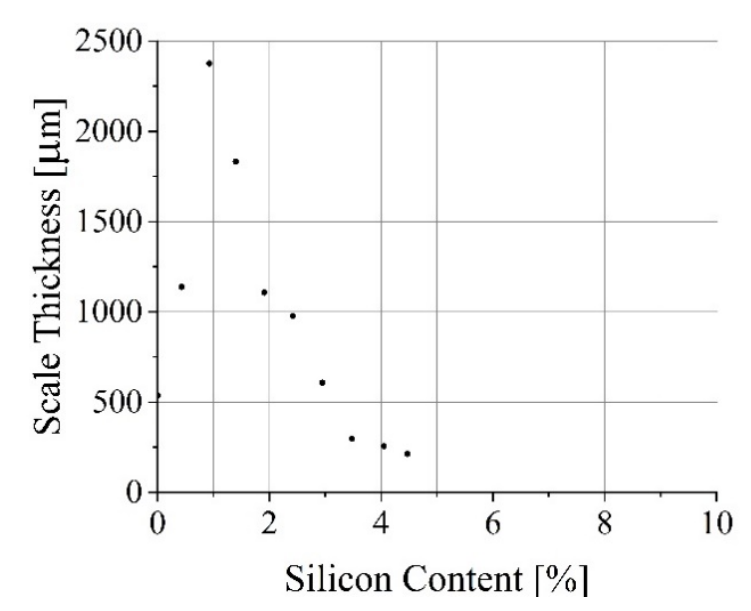

(a) Alloying element silicon

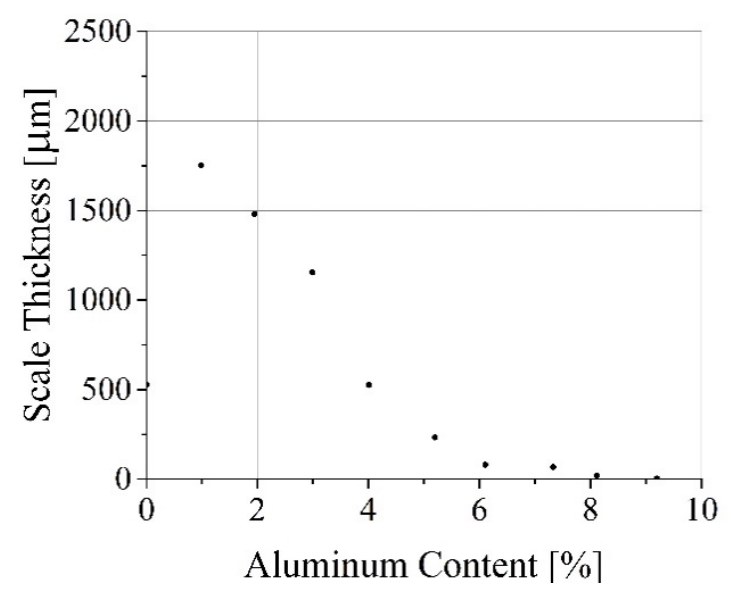

(b) Alloying element aluminum

Figure 5: Influence of silicon and aluminum on scale thickness

Generally, the oxidation of alloyed cast iron decreases with increasing silicon and aluminum content. The layer thickness decreases from almost $2.5 \mathrm{~mm}$ to less than $3 \mu \mathrm{m}$ for high silicon and aluminum alloyed cast irons, which is shown in Fig. 5. In this picture also an almost linear dependency can be seen between 1 and 3.5wt.-\% Si with a decrease in scale thickness of $790 \mu \mathrm{m}$ per percent silicon and between 1 and $6 \mathrm{wt} .-\%$ aluminum with a decrease of $350 \mu \mathrm{m}$ per percent aluminum. As already mentioned, there is a limitation in silicon and aluminum content when the material properties change to a brittle behavior. The reason for the brittleness of the material is the formation of a B2- and for higher silicon contents D03-sublattice [7]. Aluminum can also form such structures in the iron lattice, which may be confirmed in a future investigation. In the current research, the $\mathrm{Si}$ and $\mathrm{Al}$ contents were limited to 4.5 and $7 \mathrm{wt} .-\%$ respectively, otherwise the material would become almost unmachinable.

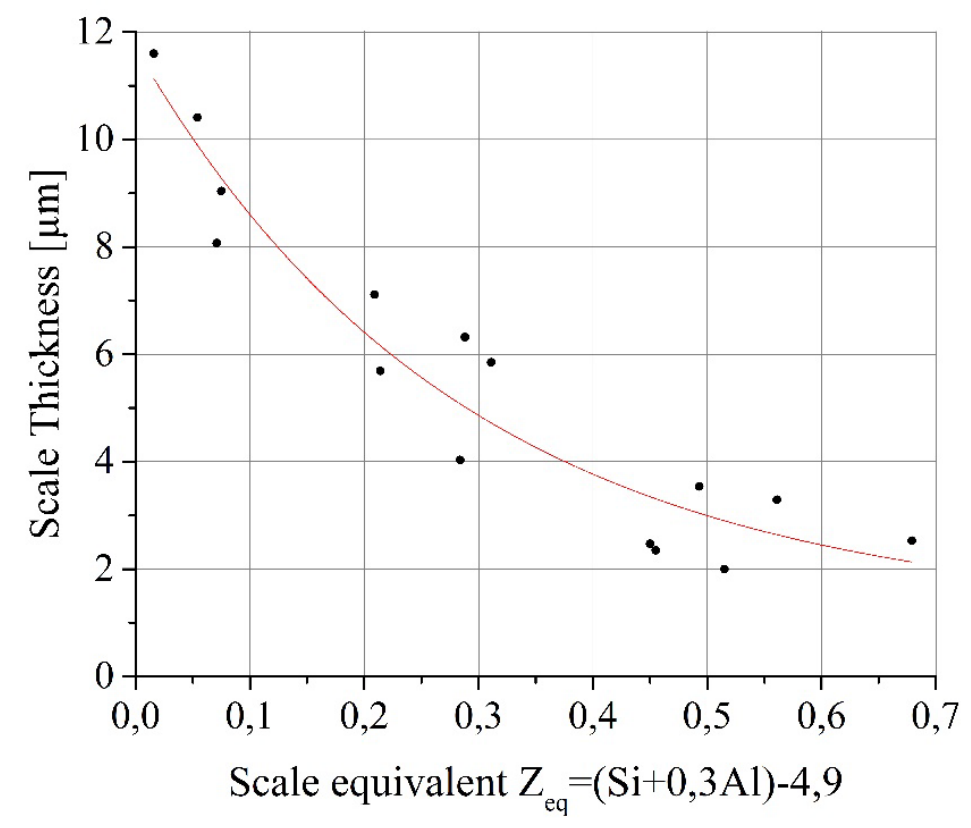

Figure 6: Scale equivalent $Z_{\mathrm{eq}}$ - layer thickness dependency

In Fig. 6 there is a logarithmical dependency shown between the scale thickness and a calculated Scale-equivalent $\mathrm{Z}_{\mathrm{eq}}$ :

$$
\mathrm{Z}_{\mathrm{eq}}=\mathrm{x}=(\mathrm{Si}+0,3 \mathrm{Al})-4,9 \text {. }
$$


The contents of silicon and $30 \%$ of the aluminum content are summed up and 4,9 is subtracted to find a vanishing point for which this relationship is valid. Why this zero point was chosen will be explained in equation (3), (4) and (5). This relationship is useful for the calculation of scale thicknesses of high silicon and aluminum alloyed cast irons with a $Z_{\mathrm{eq}}$-value larger than 0 and a similar amount of other alloying elements, e.g. chromium. By using equation (2) the expected scale thickness in $\mu \mathrm{m}$ can be calculated for different silicon and aluminum contents:

$$
f(x)=0,635-4,164 * \ln (x+0,057) .
$$

The maximum deviation is at least $1,25 \mu \mathrm{m}$. How far this relationship is also valid for lower scaleequivalents has to be analyzed in future experiments. But those lower ratios are not the center of investigation in this research because of the too low transformation temperature, that is resulting from low $\mathrm{Al}$ and Si contents. Ferrite austenite transformation temperature can be calculated by the following equation (3):

$$
\mathrm{T}_{\mathrm{tr}}=723^{\circ} \mathrm{C}+31,23 \mathrm{~K} * \% \mathrm{Si}+21,27 \mathrm{~K} * \% \mathrm{Al} \text {. }
$$

The values for the influence on the transformation temperature were determined by alloying silicon and aluminum in steps of $1 \mathrm{wt} .-\%$ to a cast iron with 3,1wt.- $\%$ C. The vanishing point was, at first, calculated because of the aim to reach an application temperature of $950^{\circ} \mathrm{C}$ and a buffer of $10^{\circ} \mathrm{C}$. The second reason was that a maximum of $7 \mathrm{wt} .-\%$ Al was determined that could be used for increasing the tensile tension at elevated temperatures without weakening the material too much because of too high brittleness at room temperature. The vanishing point can be calculated by:

$$
\mathrm{T}_{\mathrm{tr}}>950^{\circ} \mathrm{C}+10^{\circ} \mathrm{C}=960^{\circ} \mathrm{C}=723^{\circ} \mathrm{C}+31,23 \mathrm{~K} * \% \mathrm{Si}+21,27 \mathrm{~K} * 7,
$$

and:

$$
\% \mathrm{Si}+0,3 * \% \mathrm{Al}=2,82+0,3 * 7 \cong 4,9 .
$$

In Fig. 7 the comparison of scale thickness between the austenitic cast iron D5S $-141.5 \mu \mathrm{m}$ (a) and a high aluminum and silicon alloyed cast iron $-8,7 \mu \mathrm{m}$ (b) is shown. The ferritic cast iron has two big advantages in oxidation resistance. At first it forms much thinner oxide scales. The second benefit is the much better spalling behavior of the less brittle and more adherent scales of the ferritic cast iron. In that way physical damage to the casting itself can be prevented by less detached oxide particles.

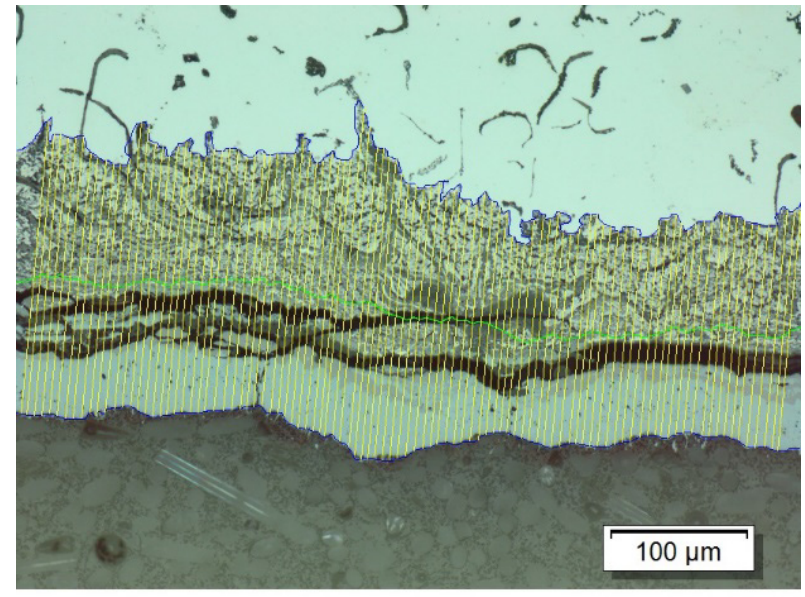

(a) Oxide scale D5S

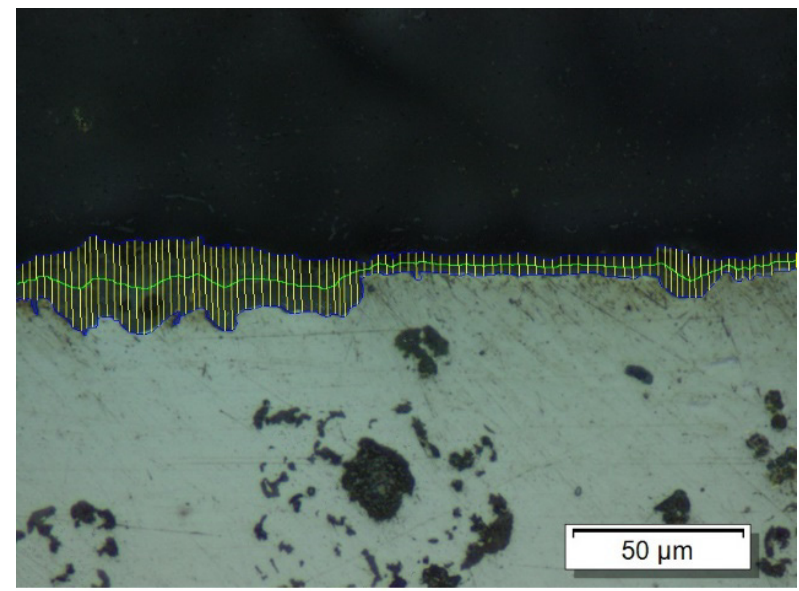

(b) Oxide scale CI-SiMoAl

Figure 7: Oxide scales of the compared austenitic and ferritic cast irons

\section{Conclusion and Outlook}

In conclusion high silicon and aluminum alloyed cast iron is attractive for usage in high temperature application. Although there are some deficits to mention. At first, it is hard to control and to keep 
the graphite morphology in close borders and secondly, the brittleness of this material at room temperature is a grave subject to handle and to control.

In summary the benefits of the material exceed the deficits. At first it has an extremely high oxidation resistance, much better than austenitic cast irons. This results in a longer life time of the casting and better performance during the life time related to the efficiency. The second benefit is that it is more economic. The material costs are one fourth of the costs of an austenitic cast iron because of the nickel savings. Furthermore, the density is lower, which makes it attractive for lightweight construction. One more benefit is the high temperature stability due to kappa-phase precipitation which results in good tensile strength at elevated temperatures.

In future the research will focus more and more on the mechanical properties of the material. Furthermore, there will be some analyzations for the oxide scale adhesion to compare the clingage of oxide layers of different alloys and to better quantify the difference between D5S and other materials.

\section{References}

[1] I. Anžel, High Temperature Oxidation of Metals and Alloys, Metalurgija - Journal of Metallurgy 13 (2007) 325-336.

[2] M.B.G. Castro et. al, A thermodynamic approach to the compatibility of materials combinations for recycling, Resources, Conservation and Recycling 43 (2004) 1-19.

[3] M. J. Kadhim, Microstructure and High Temperature Oxidation Behavior of Aluminum Alloyed Cast Irons, Modern Applied Science 4 (2010) 130-135.

[4] S. Ghosh, A. Prodhan, N. Mohanty and A. K. Chakrabarti, A Study on the Oxidation Characteristics of Cast Irons Containing Aluminum, Oxid Met 45 (1996) 109-131.

[5] C. Bartels, R. Gerhards, H. Hanselka, and K. Herfurth, Gusseisen mit Kugelgraphit: Herstellung - Eigenschaften - Anwendung, Konstruieren + Giessen 32 (2007) 1-98.

[6] A. R. K.Rashid, D. V. Edmonds, Oxidation behaviour of Al-alloyed ductile cast irons at elevated temperature, Surf Interface Anal 36 (2004) 1011-1013.

[7] P. Weiß, J. Frieß, M. Riebisch, B. Pustal, A. Bührig-Polaczek, Werkstoff- und Prozessoptimierung für mischkristallverfestigtes Gusseisen mit Kugelgraphit, 42. Aachener Gießereikolloquium, (2016) 